\title{
Analysis of Aspects Required to Improve Customer Experience in Indonesia's Internet Broadband
}

\author{
Wendy Junaidi \\ International Business Management Department, School of Business Management \\ Bina Nusantara University \\ Jakarta 11480, Indonesia \\ wendy.junaidi@binus.ac.id \\ Correspondence: wendy.junaidi@binus.ac.id
}

\begin{abstract}
In the digital age, transactions range from hailing a taxi to watching TV shows on demand that depend on an internet connection. As consumers have more power than ever before, today's internet service providers face more demanding service expectations from customers than in the past, they recognize the need to improve certain aspects of business, including the quality of the experience they provide to customers. In other words, meeting the demands of broadband internet has its own challenges. The purpose of this study is to provide insights regarding challenges along the customer journey as the opportunities for improvement. The results showed that longer time from ordering to installation and frequent network disconnection are prioritized customer experience issues in internet broadband business and service providers need to focus on improving on the way companies engage the customers through reliable touch points and resetting the way people work in the organization to be more customer-centric.
\end{abstract}

Keywords: Internet Broadband; Customer Experience; Customer Journey

\section{INTRODUCTION}

\section{Research Background}

In the constantly changing internet broadband landscape the market is becoming increasingly saturated with various range of products and services, as service providers compete for market share and seek new growth opportunities. With the increasing choice of internet broadband products and services for consumers, providing a great customer experience has become less straightforward. In fact, customer experience is a critical differentiating aspect of many offerings.

Operators have been actively investing in creating a better customer experience for many years now - developing a customer-centric culture, improving processes and leveraging data in more effective ways to understand customer experience and identify trouble spots. Although internet broadband subscriptions in Indonesia have shown dramatic increase with 370\% growth over the past 10 years (Figure 1), customer needs and expectations are evolving and internet service providers need to continuously learn and adapt to serve the customers, meaning that there are no static goals. Furthermore, providing a great customer experience has been a never-ending quest. How happy customers are is the difference between successful retention and painful attrition. And that level of happiness depends entirely on the customer experience. 


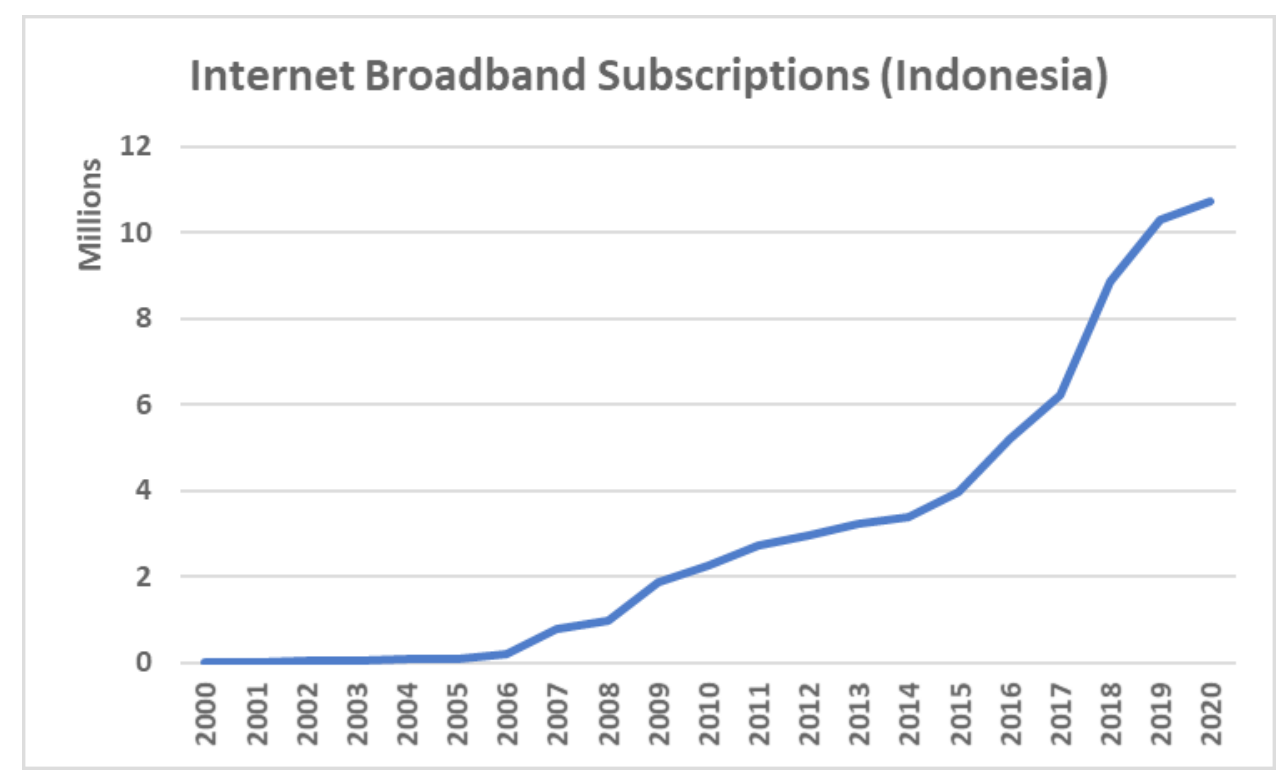

Figure 1. Internet Broadband Subscriptions - Indonesia

(Source: International Telecommunication Union, 2021)

\section{Problem Formulation}

Based on the description above, this study formulates the problem that will be answered in this study, i.e. "What are the most prioritized issues in the internet broadband business in Indonesia that need to be fixed by internet service providers in Indonesia to provide a better customer experience?"

\section{Research Objective}

This study has the objective to identify top priority issues which internet service providers in Indonesia need to fix in order to provide better customer experience.

\section{Literature Review}

Customers usually face a broad array of products and services that might satisfy their needs. Customers form expectations about the value and satisfaction that various market offerings will deliver and buy accordingly. Satisfied customers buy again and tell others about their good experiences. Dissatisfied customers often switch to competitors and spread bad word of mouth about product to others. Marketers must be careful to set the right level of expectations. If they set expectations too low, they may satisfy those who buy but fail to attract enough buyers. If they set expectations too high, buyers will be disappointed. Customer value and customer satisfaction are key building blocks for developing and managing customer relationships (Kotler and Armstrong, 2018). Customer satisfaction is essentially the culmination of a series of customer experiences. Therefore, to understand how to achieve customer satisfaction, a company must capture the impression left on the customers over the entire journey and this means that customer satisfaction depends on good customer experience given the fact that loyal customers also tend to spend more money buying from a particular organization and put more effort in promoting the company compared to a brand-new customer (Jaiswal \& Niraj, 2011). Previous internet service provider research also shows that a strategy that places the customer at the center of a company's operations has the potential to reduce the costs associated with acquiring new customers. As a result, internet service providers will be able to reduce current customer problems associated with switching to another internet service provider (Thaichon et al.,2014)

Customer experience itself is defined as "adding value for customers buying products and services through customer participation and connection, by managing all aspects of the encounter" (Kotler et al., 2013). The encounter includes touchpoints. Businesses can create and modify touchpoints so that they are suited to their consumers which changes/enhances the customers' experience. Creating an experience for the customer can lead to greater brand loyalty and brand recognition in the form of logos, color, smell, touch, taste, etc. Moreover, improving customer experience has close relationship with customer loyalty, which through the creation and maintenance of customer loyalty, companies can gain higher profit margins over a lifetime duration of the business relationship with customers (Wang \& Wu, 2012). 


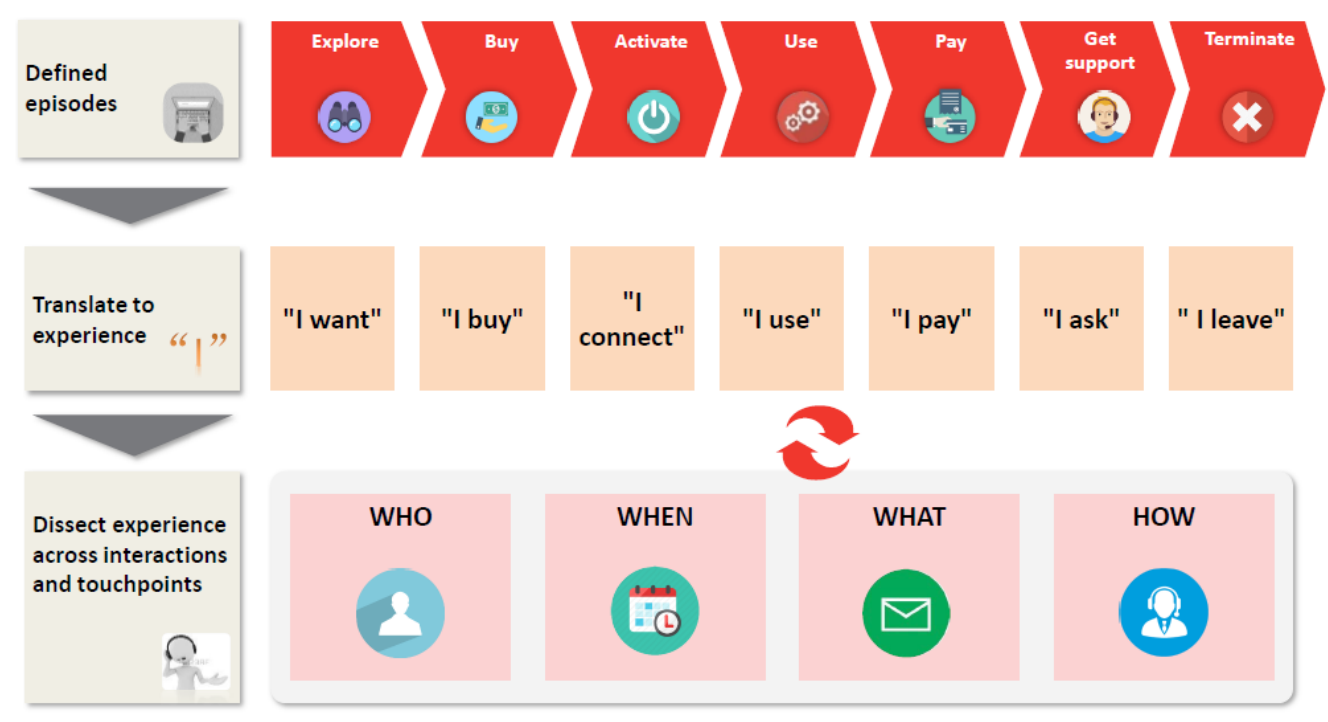

Figure 2. Customer Episode Translation to Experience

To measure the level of loyalty in each episode as shown in Figure 2, Fred Reichheld developed the net promoter score (NPS), a widely used market research metric, which usually takes the form of a single survey question that asks respondents to rate the likelihood that they will recommend a company, product or service to friends or colleagues (Reichheld, 2003). Ratings of 9 or 10 indicate promoters; 7 and 8, passives; and 0 through 6 , detractors. The NPS is simply the percentage of promoters minus the percentage of detractors.

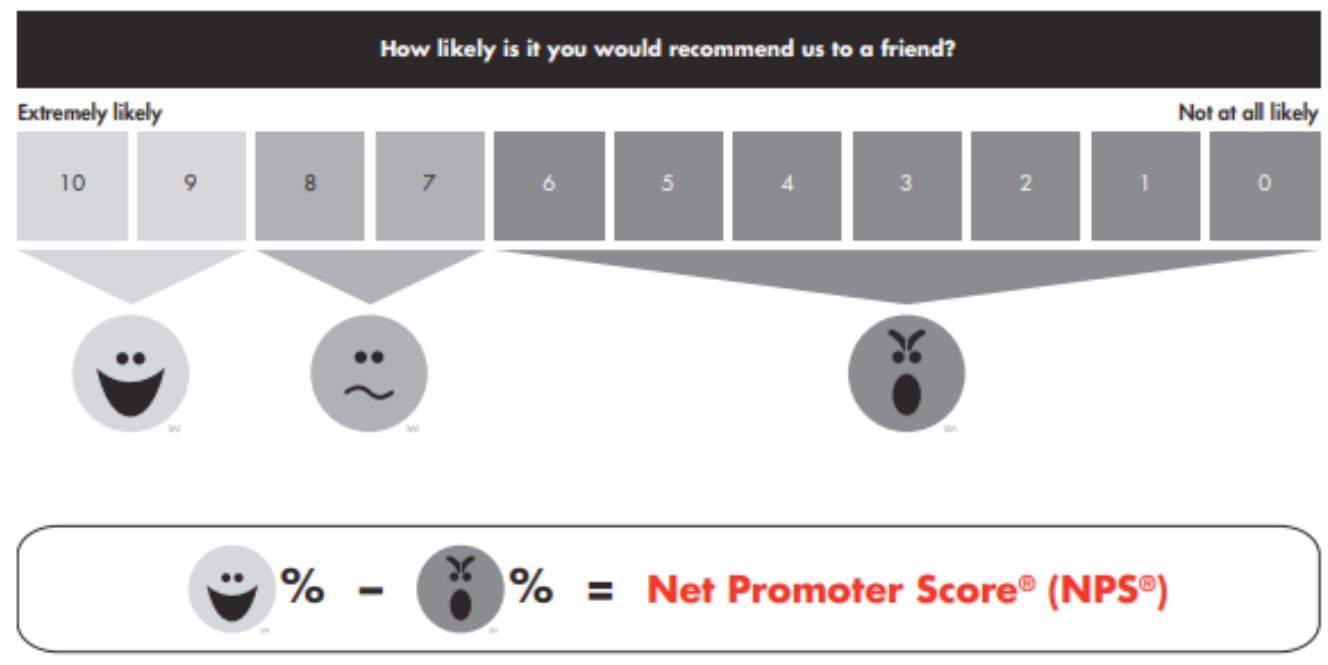

Figure 3. NPS Calculation

\section{METHODS}

According to the purpose of this study, NPS is the approach which can enhance the final result of this research study by utilizing quantitative interpretation of qualitative data points. This approach method meant to identify top priority issues which internet service providers in Indonesia need to fix in order to provide better customer experience. Data information from both primary research such as in-depth interviews and secondary research from documentation, reports, etc., were analysed by using NPS approach. The analysis process in this study is conducted when the data/information is gathered or after the data/information has been gathered. The activity qualitative model has three steps; data reduction, display data, and result and verification.

Data/information which has been through reduction process will be displayed and organized to categories. The most frequent form of display data for qualitative research data in the post has been narrative text. Two types of displaying data information for qualitative research, context chart and matrix. It helps qualitative researchers through models of displaying data using tables, graphics, flow chart, category, matrix, etc. The main data for this study came from two stakeholders, i.e. business consultant and end-users. 


\section{RESULT AND DISCUSSION}

In order to capture comprehensive insights, both discussions with consultants and in-depth interviews with respondents were conducted. During the in-depth interviews with respondents which were intended to measure the NPS scores, the author also asked about things which have or have not run well during the customer journeys. While gathering the scores on the likelihood of the respondents to recommend the products they subscribed to, a question about what have or have not run well with the products during customer journey was asked to respondents to populate the customer experience issues. As a key takeaway, there are several problems identified in the customer journey identified in this study, which are:

1. "Clarity of invoice details", which refers to how difficult it is for customers to understand the contents of invoice details.

2. "Time to get served", which refers to the length of time it takes to serve the customer starting from the time when he/she submits the queries to the internet service providers.

3. "Easiness to get the information needed", which refers to how easy it is for prospects or customers to get the information needed in the specific customer journey.

4. "IPTV screen resolution quality", which refers to how good the resolution quality of IPTV services is.

5. "Time from order to installation", which refers to the length of time it takes the customer to start enjoying the service starting from the time when he/she submits the request for installation.

6. "Punctuality of installation visit", which refers to the technician's ability to fulfill the commitment of installation visit in a timely manner.

7. "Complaint-to-resolution time", which refers to the length of time required to resolve customer complaint starting from the time when the report is received by internet service provider.

8. "Internet speed", which refers to how much data the connection can download (download speeds) or upload (upload speeds) per second.

9. "Availability of preferred IPTV channel", which refers to the availability of IPTV channels that customers want to watch.

10. "Network disconnection frequency", which refers to the frequency of network interruption which can still be tolerated by the customer.

11. "Payment method options", which refers to the availability of payment method which the customer wants to use to pay the invoice.

Among those 11 problems described above, there are several important problems in the customer journey which most respondents complained about and need to be fixed by the internet service providers, i.e., time to get served (Explore and Buy episodes), time from order to installation (Activate episode), network disconnection frequency (Use episode), internet speed (Use episode), and complaint-to-resolution time (Get Support episode).

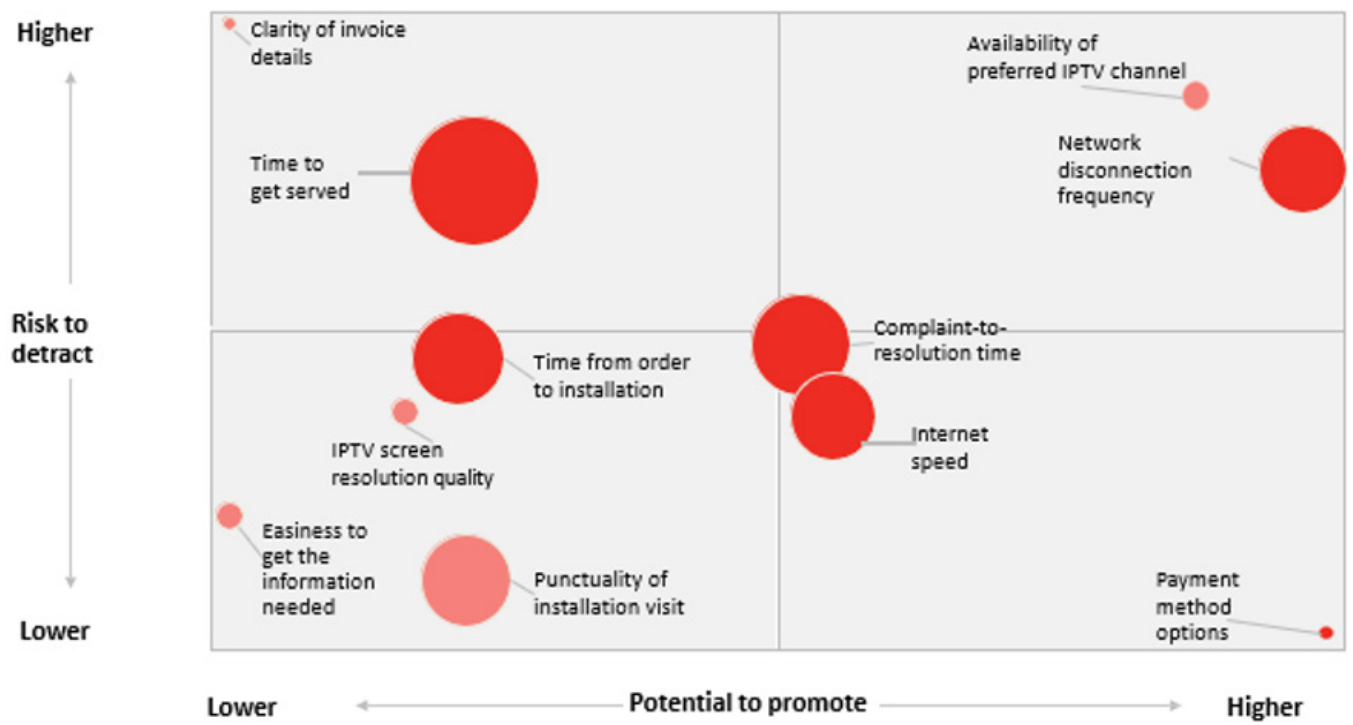

Figure 4. Prioritization of Customer Experience Issues 
The bubble chart in Figure 4 correlates 3 data dimensions, namely "NPS", "potential to promote the product to others", and "risk to detract" from each identified problem in customer journey, where the bubble size is determined by the NPS value obtained in the surveys: a lower NPS score will be indicated by a larger bubble size. It also helps the author identify problems which have an impact on the possibility of internet subscribers to stop using the service: time to get served and network disconnection.

With the help of root cause analysis, the customer experience problems mentioned above are caused by a sub-optimal order management process with incomplete order tracking, poor customer expectations management, inaccurate database infrastructure, together with high turnover and inadequate training.

\section{CONCLUSION}

There are two key takeaways from this study as suggestion for internet service providers in Indonesia to focus on. Firstly, we have observed that the market requires the improvement in the way the internet service providers are engaging with customers, through expanded and seamless customer touchpoints (both traditional and digital), automation and simplification across touchpoints, and personalized, targeted and interactive experience.

Secondly, resetting the way people work in the organization to be more customer-centric is required, including customer-centric measurement and reporting, back-end processes, systems and tools enhancement, operating governance, resource allocation, and trainings.

As this study was conducted in a pandemic situation, most of the insights were gathered through online interviews so there is a possibility that insights from the elderly or respondents who live in the area are not captured optimally. Hence, the author gives suggestion to the further research in the future in order to provide better results and impact for business, such as combining both face to face and online interviews, providing incentives to the respondents as an appreciation for filling out questionnaires as well as identifying more customer experience issues as customer needs are constantly evolving resulting in intense business competition.

\section{REFERENCES}

Bain \& Company, Inc. (2016). Loyalty Insights Introducing: The Net Promoter System. Retrieved from https:// www.bain.com/contentassets/a0e49354bbe74390831ae2b899be35d1/loyalty_insights_1_introducing_ the_net_promoter_system_update.pdf

Jaiswal, K., \& Niraj, R. (2011). Examining Mediating Role of Attitudinal Loyalty and Nonlinear Effects in Satisfaction-Behavioral Intentions Relationship. Journal of Services Marketing, 25, 165- 175.

Kotler, P., Burton, S., Deans, K., Brown, L., \& Armstrong, G. (2013). Marketing (9 $9^{\text {th }}$ ed.). NSW, Australia: Pearson Australia.

Kotler, P., \& Armstrong, G. (2018). Principles of Marketing. (15 ${ }^{\text {th }}$ ed.). Global Edition. Pearson.

Reichheld, Frederick F. (2003). One Number You Need to Grow. Harvard Business Review. PMID 14712543

Thaichon, P., Lobo, A. and Mitsis, A. (2014). Achieving Customer Loyalty Through Service Excellence in Internet Industry. International Journal of Quality and Service Sciences, Vol. 6 No. 4, pp. 274-289

Wang, C. and Wu, L. (2012). Customer Loyalty and The Role of Relationship Length. Managing Service Quality: An International Journal, Vol. 22 No. 1, pp. 58-74. 